\title{
9. An intelligent agent-assisted logistics exception management decision support system: a design- science approach
}

\author{
SHIJIA GAO \\ DONGMING XU \\ UNIVERSITY OF QUEENSLAND
}

\section{Abstract}

With the increased complexity and uncertainty in business operations, adaptive and collaborative business processes and exception management (EM) are gaining growing attention. In the logistics industry, the current logistics exceptions are managed using human resources together with the traditional workflow technology-based supply-chain management or other logistics tools. The traditional workflow technology models and manages business processes and anticipated exceptions based on predefined logical procedures of activities from a centralised perspective that offers inadequate decision support for flexibility and adaptability in EM. These procedures are limited when monitoring logistics activities in real time in order to detect and resolve the exceptions in a timely manner. In order to mitigate these problems, a design-science research approachspecifically an intelligent-agent decision support approach in logistics EM-has been proposed and investigated in this research. It contains three interrelated research phases. The first research phase focuses on the conceptualisation of the logistics EM. It consists of two parts. The first part is logistics exception classification, in order to enable more efficient decision support practices for logistics EM. The second part focuses on the development of the conceptual framework (an artefact) for design and development of logistics EM systems for decision making. The second research phase focuses on the formalisation of the conceptual framework. A multi-agent-based logistics EM system is designed based on the conceptual framework. The third research phase will focus on the 
development of the designed logistics EM artefact. It will include two stages. First, a prototype will be developed. To provide more adaptive, flexible and collaborative decision support, the intelligent agent technology will be used for implementation. Second, the prototype will be evaluated via social-science research methods: semi-structured interviews and laboratory experiment. It is proposed that this theory-driven agent-based logistics EM system will provide more efficient and timely decision-making support for managers in relation to logistics EM. The designed artefacts and the research design are the major contributions of this research, which add knowledge to design-science research theory and practice. The conceptualisation-formalisation-development research approach can be applied in other similar IS design-science research.

\section{Introduction}

Businesses today around the world are facing the challenges of a rapidly changing environment due to the development of new business markets and technology. The business climate is changing from centralised and closed to distributed and open (Wang and Wang 2006). Today's changing and distributed environment is full of complex and dynamic business processes. Moreover, the unpredictability of business processes requires that business applications support exception management (EM) with the ability to adapt dynamically to the changing environment. An exception is any phenomenon that prevents the successful completion of normal business processes (Klein et al. 2000). Traditional approaches dealing with EM are based on workflow technology and business process redesign. Traditional approaches provide inadequate support for flexibility and collaboration in EM (Jennings et al. 2000; Klein and Dellarocas 2000) and they can cost a lot in business process redesign or reconstruction.

Logistics is one example of this situation. According to Becker (2000), companies can lose between 9 per cent and 20 per cent of their share value over a sixmonth period due to logistics exceptions. The logistics exceptions have various consequences such as delayed production, increases in costs or decreases in customer satisfaction (Huhns et al. 2002). In order to minimise the exception consequences, it is crucial to detect and handle exceptions appropriately. In current practice, most exceptions are managed using the knowledge and skills of working professionals together with traditional workflow technologybased supply-chain management or logistics tools (Dellarocas and Klein 2000; Dellarocas et al. 2000; Huhns et al. 2002). Workflow technology, however, offers inadequate flexibility and adaptability in EM (Wang and Wang 2006). Moreover, it is limited when monitoring business activities in real time in order to detect and resolve the exceptions in a timely manner. 
EM in logistics is a complex, dynamic and distributed process. To provide decision support for logistics EM in real time, business activity monitoring (BAM) is deployed in a three-layered architecture (Dresner 2003). BAM is the real-time reporting, analysing and alerting of significant business events (that is, exceptions) accomplished by gathering data, key performance indicators (KPIs) and business events from multiple applications (Dresner 2003). In addition, a system designed for real-time distributed logistics EM requires a high degree of cooperative problem-solving capability. Thus, it is very important to start from a decision-making/problem-solving perspective when analysing and representing logistics EM domain knowledge. In this study, to inform the design of a logistics EM system, we have adopted Simon's (1977) decision-making/ problem-solving process theory and the Cynefin sense-making framework (Snowden 2002) to classify the logistics exceptions and use different decisionmaking strategies to tackle them. Then, in order to overcome the limitations of the traditional workflow technology solutions, we will apply intelligent agent (IA) technology to logistics EM by taking advantage of the agent's autonomy, reactivity, proactivity and social ability. System development is fundamentally a process of design (Hevner et al. 2004). This chapter reports a design-science research study that attempts to provide a real-time decision-support mechanism to monitor and handle logistics exceptions in a more effective and efficient way.

The organisation of this chapter is as follows. First, the design-science research approach employed in this study is presented. Next, the relevant literature is briefly reviewed. Section four identifies and classifies logistics exceptions. Based on a logistics EM conceptual framework presented in section five, the design of a multi-agent-assisted decision-support system for EM in the logistics domain is proposed in section six. Section seven describes the planned evaluation for the designed artefacts. Section eight concludes the chapter.

\section{Design science as a research method}

As mentioned in the introduction, this research has created and will evaluate a logistics EM conceptual framework and a decision-support system. The research uses a design-science approach. Design science 'is an alternative, or complement, to the natural science approach that is dominant in information systems (IS) research' (Arnott 2006:57). In design science, the researcher 'creates and evaluates IT artefacts intended to solve identified organizational problems' (Hevner et al. 2004:77). March and Smith (1995:253) clearly draw the distinction between natural and design science: 'Whereas natural science tries to understand reality, design science attempts to create things that serve human purposes.' 
Design science is particularly relevant to IS research (Arnott 2006). Figure 9.1 presents the research approach used in this chapter. On the left-hand side of the figure are five distinct research processes. These are adapted from Nunamaker et al. (1991), who propose an IS development process model. This process model is consistent with aspects of other frameworks and models for conducting design-science research in IS. For example, this process model can be seen to map onto Gregg et al.'s (2001) IS design-science software engineering research methodology (SERM) framework. SERM comprises three interrelated phases: conceptualisation, formalisation and development. Gregg et al. (2001) argue that rigorous design research must address at least two of the three phases. In Figure 9.1, 'conceptualisation' is the construct a conceptual frameworkstep, 'formalisation' is covered by develop a system architecture and analyse and design the system steps, and 'development' is addressed by building and evaluating the system. In addition, March and Smith (1995) propose build and evaluate as the two fundamental design research processes. Build effectively covers the first four processes in Figure 9.1. Teasing out build into four sub-processes makes the research design much clearer and the execution much easier.

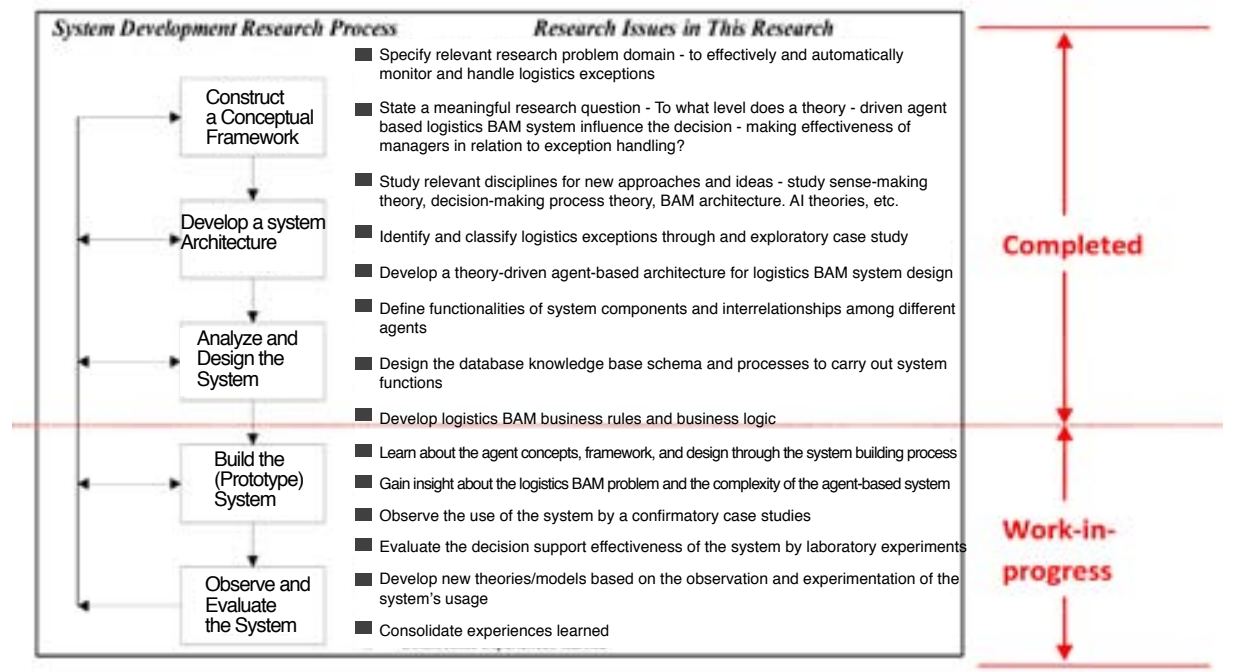

Figure 9.1 Issues in the system development research process in this research

Adapted from Nunamaker et al. (1991)

The right-hand side of Figure 9.1 shows how the current research uses the design-science methodology based on Nunamaker et al.'s (1991) IS development process model. Research issues that should be addressed in each stage in this research are identified. Currently, the first three steps have been completed 
while the last two steps are still in progress. The details of each process step are presented in the rest of this chapter. The next section is the literature review of the theoretical foundations for constructing the conceptual framework.

\section{Literature review}

\section{Exception management in logistics business processes}

The occurrence of exceptions is a fundamental part of business activities. In order for business management systems to support such unpredictability they must support exception handling with the ability to adapt to today's dynamic, uncertain and error-prone environment (Kammer et al. 2000). Because business exceptions are related mostly to business activities or business processes, most efforts to handle exceptions have utilised workflow technology to include conditional branches in the workflow model or redesign business systems to deal with anticipated exceptions. Such approaches, however, offer limited support for flexibility and collaboration during process management (Jennings et al. 2000; Klein and Dellarocas 2000) and they can cost a lot in business process redesign or reconstruction. Several techniques have been suggested for supporting exception handling in workflow systems and to dynamically adapt to the changing environment - for example: knowledge-based approaches, run-time dynamism, configurable execution, reflexivity, evolving models from workflow instances, and the like (Klein et al. 2000). While providing mechanisms for the seamless integration of exception handling into workflow descriptions, such approaches lack the consideration of practical aspects that become important in workflow systems such as the participation of autonomous, heterogeneous legacy systems and the strong impact of human intervention. EM is a complex and dynamic process and collaborations between logistics partners are usually required in such activities. If a system has to cope with undefined errors or failures, or there is a need for real-time collaboration, more flexible and robust approaches are needed (Moitra and Ganesh 2005).

Gartner Inc. (McCoy 2002) defines business activity monitoring (BAM) as providing real-time access to critical business performance indicators to improve the speed and effectiveness of business operations. BAM encompasses the realtime reporting, analysis and alerting of significant business events, accomplished by gathering data, KPIs and business events from multiple applications (Dresner 2003). Unlike traditional real-time monitoring, BAM draws its information from 
multiple application systems and other internal and external (inter-enterprise) sources (Nesamoney 2004), enabling a broader and richer view of business activities (McCoy 2002).

Manufacturing and logistics companies are among the most open-minded and willing to be early adopters of BAM (McKeefrey 2002). According to Parameswaran (2004), the benefits of a BAM solution to the logistics industry are that it

- enables operational managers to receive alerts from the existing IT applications when a snag occurs

- informs on-duty personnel about last-minute shipment changes

- alerts truck drivers when the perishable goods they are carrying will waste if they are stopped

- plans deliveries

- manages containers

- checks profit and loss

- performs maintenance and repairs

- tracks perishable goods

- identifies underutilised space.

It is clear that there are many benefits for the logistics industry in deploying BAM solutions, but what functionality is required to deliver a BAM architecture or a BAM solution? Gartner provides a layered BAM logical architecture (Dresner 2003), shown in Figure 9.2. Business events are fed into an event absorption layer and filtered, then processed against rules that, when met, generate exceptions. The exceptions are delivered: an action is triggered or a display is fed. This architecture provides the base to develop the logistics EM conceptual framework and system architecture.

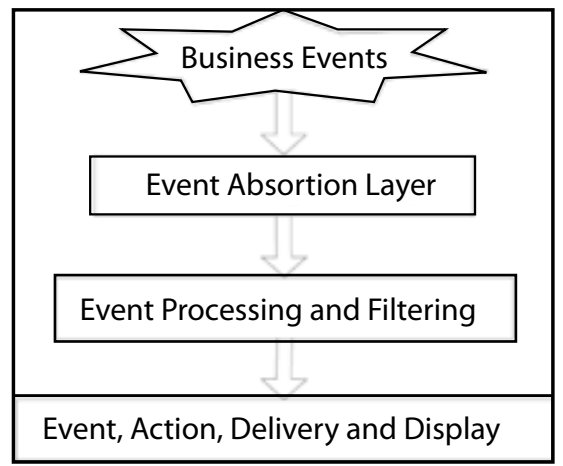

Figure 9.2 Gartner's BAM architecture

Source: Dresner (2003:8) 


\section{Intelligent agents technology and its business application}

According to Dresner (2003), one technology that can be used to design and develop the logistics BAM/EM system is that of intelligent agents (IA), which can overcome the limitations of the traditional workflow technology solutions. In the past decade, the study and use of IAs have gained popularity among IS researchers (Jennings 2000). IA is a software-based computer system that is capable of flexible action in order to meet its design objectives, where flexibility includes properties such as autonomy, social capability, reactivity and proactivity (Wooldridge 2002; Wooldridge and Jennings 1995). A multiagent system consists of a group of agents that interact with one another to collectively achieve their goals (Jennings and Wooldridge 1998). By absorbing other agents' knowledge and capabilities, agents can overcome their inherent bounds of intelligence.

In recent years, there has been considerable growth of interest in the design of a distributed, intelligent society of agents capable of collaboratively dealing with complex problems and vast amounts of information (Kuo and Lin 2000). Because agent technology provides flexible, distributed and intelligent solutions for business applications, researchers have proposed numerous IAbased business systems (Gao et al. 2005, 2007; Vahidov and Fazlollahi 2004; Wang et al. 2002). The benefits of an IA approach are its flexibility, adaptability and decentralisation.

Agent-based systems are well suited for EM (Liu et al. 2001; Wang et al. 2002). IAs can be deployed with specific EM domain knowledge and they can intermediate on behalf of business EM analysts by being able to perform numerous, error-free calculations. IAs can also aid rapid interpretation of the precise requirements of business managers regarding EM (Wang et al. 2002).

\section{Decision-making mechanisms}

Real-time EM in logistics is a complex, dynamic and distributed process. Therefore, a system designed to support logistics EM decision making requires a high degree of cooperative problem-solving capability. Accordingly, one problem-solving/decision-making process and one sense-making framework are reviewed and they form the theoretical foundations that inform the design in this research.

\section{Herbert Simon's decision-making/problem-solving process theory}

According to Vahidov (2005), productive human decision support system collaboration can be achieved if the system is organised to fit human decision- 
making processes. Simon's (1977) model of the decision-making/problem-solving process fits human decision-making processes very well. Simon's (1977) model comprises four distinct phases - intelligence, design, choice and reviewshown in Table 9.1. Although generic and simple in nature, Simon's model has been applied and validated in a wide array of situations, such as optimisation models (Dutta 1996), crisis problem finding (Gallupe et al. 1988) and investment optimisation (Gao et al. 2007; Vahidov and Fazlollahi 2004).

\section{Table 9.1 Simon's decision-making/problem-solving phases}

\begin{tabular}{|l|l|}
\hline Phase & Description \\
\hline Intelligence & $\begin{array}{l}\text { The decision maker gathers information about the situation and } \\
\text { recognises the problem at hand. }\end{array}$ \\
\hline Design & $\begin{array}{l}\text { The decision maker structures the problematic situation, develops criteria } \\
\text { and identifies the various alternatives through which the problem can be } \\
\text { solved. }\end{array}$ \\
\hline Review & $\begin{array}{l}\text { The decision maker chooses the best alternative that meets the criteria } \\
\text { and makes the final decision. }\end{array}$ \\
\hline & $\begin{array}{l}\text { The decision maker uses the feedback from the results of the decision } \\
\text { to review how well the process was executed. Such reflection on past } \\
\text { processes can form a basis of the intelligence phase for future decisions. }\end{array}$ \\
\hline
\end{tabular}

\section{The Cynefin sense-making framework}

The Cynefin framework is a sense-making device originating in the practice of knowledge management (Snowden 2002). It has been applied extensively in consultancy and action research in management (Stewart 2002), strategy (Snowden 2004), health care (Mark 2006), policymaking ( $\mathrm{O}^{\prime}$ Neill 2004), product development, branding, customer relationship management and supply-chain management (Kurtz and Snowden 2003).

The Cynefin sense-making framework helps people make sense of complexities. It has five domains, four of which are named, and a fifth central area that is the domain of disorder-occupied by those who have no awareness of their context. The details of the four named domains are shown in Table 9.2 (Kurtz and Snowden 2003; Snowden 2002).

\section{Table 9.2 The Cynefin sense-making framework domains}

\begin{tabular}{|c|c|c|}
\hline $\begin{array}{l}\text { Domain } \\
\text { name }\end{array}$ & Explanation & Decision model \\
\hline Known & $\begin{array}{l}\text { Known causes and effects. Cause and effect } \\
\text { relationships are generally linear. It is the } \\
\text { only legitimate domain of best practice. } \\
\text { Within known limits, we can both predict } \\
\text { and prescribe behaviour. }\end{array}$ & $\begin{array}{l}\text { To sense incoming data, } \\
\text { categorise that data and then } \\
\text { respond in accordance with } \\
\text { predetermined practice. }\end{array}$ \\
\hline
\end{tabular}




\begin{tabular}{|l|l|l|}
\hline Knowable & $\begin{array}{l}\text { Knowable causes and effects. While stable } \\
\text { (that is, complicated but linear) cause and } \\
\text { effect relationships exist in this domain, they } \\
\text { might not be fully known or they might be } \\
\text { known only by a limited group of people. }\end{array}$ & $\begin{array}{l}\text { To sense incoming data, } \\
\text { analyse that data and then } \\
\text { respond in accordance with } \\
\text { expert advice or interpretation } \\
\text { of that analysis. }\end{array}$ \\
\hline Complex & $\begin{array}{l}\text { Complex relationships. There are cause and } \\
\text { effect relationships between the agents, but } \\
\text { both the number of agents and the number } \\
\text { of relationships defies categorisation or } \\
\text { analytical techniques. Emergent patterns can } \\
\text { be perceived but not predicted. }\end{array}$ & $\begin{array}{l}\text { To create probes to make the } \\
\text { patterns or potential patterns } \\
\text { more visible (sense) before we } \\
\text { take any action (respond). }\end{array}$ \\
\hline Chaos & $\begin{array}{l}\text { There are no perceivable relationships. The } \\
\text { system is turbulent. There is nothing to } \\
\text { analyse, and waiting for patterns to emerge } \\
\text { is a waste of time. }\end{array}$ & $\begin{array}{l}\text { To act, quickly and decisively, } \\
\text { to reduce the turbulence, and } \\
\text { then to sense immediately the } \\
\text { reaction to that intervention } \\
\text { so that we can respond } \\
\text { accordingly. }\end{array}$ \\
\hline
\end{tabular}

\section{Logistics exceptions classification}

Based on the above reviewed Cynefin sense-making framework, in this section, logistics exceptions are examined, identified and classified.

\section{Exception analysis}

In this research, exception analysis was conducted in two ways. First, the logistics exceptions were reviewed through the literature. Second, a single exploratory case study in a major logistics company in Australia was conducted to investigate how the exceptions happened in daily business process/operations. The logistics company was chosen because it was an internationally recognised and leading logistics provider and the single case study design was chosen because this logistics company was representative (Yin 2003:41). The data were collected from June to September 2007, in the electronic team of the logistics company, and following Yin's (2003) case study methodology rigorously. All eight team members (six female; two male), including one team manager, were interviewed. The interviews were semi-structured (semi-structured interviews are considered most appropriate as they are often used in exploratory research [Yin 2003]) and lasted from one to two hours each. All interviews were audio recorded and notes were also taken. Key interviews were fully transcribed, thematically coded by two researchers by using QSR NVivo Version 7.0 software and analysed manually. In synthesising the literature review with the findings from the case study, six exceptions in logistics operations were identified. Based on the results of the case study, for each logistics exception, related causes were identified and current handling methods summarised. In addition, the problems of the current exception handling methods were identified and they will be 
addressed subsequently. The corresponding literature references that indicate the same logistics exceptions were also summarised. Two example exceptions are shown in Table 9.3. ${ }^{1}$

\section{Table 9.3 Analysis of logistics exceptions, related causes and handling methods}

\begin{tabular}{|c|c|c|c|c|}
\hline \multirow{2}{*}{$\begin{array}{l}\text { Exception } \\
\text { description }\end{array}$} & \multicolumn{2}{|c|}{ Logistics company examples } & \multirow{2}{*}{$\begin{array}{l}\text { Problems of } \\
\text { current exception } \\
\text { handling methods }\end{array}$} & \multirow[b]{2}{*}{ References } \\
\hline & $\begin{array}{l}\text { Causes of the } \\
\text { exception }\end{array}$ & $\begin{array}{l}\text { Current exception } \\
\text { handling methods }\end{array}$ & & \\
\hline $\begin{array}{l}\text { Delayed } \\
\text { delivery or } \\
\text { no delivery }\end{array}$ & $\begin{array}{l}\text { Weather factor- } \\
\text { for example, storm } \\
\text { Traffic } \\
\text { Change to routes, } \\
\text { which take longer } \\
\text { to the destination } \\
\text { Space-allocation } \\
\text { problem } \\
\text { Human factor-for } \\
\text { example, driver is } \\
\text { sick } \\
\text { The customs not } \\
\text { cleared }\end{array}$ & $\begin{array}{l}\text { Use alternative } \\
\text { routes to get to } \\
\text { the destination } \\
\text { quicker } \\
\text { Use different } \\
\text { transport mode for } \\
\text { delivery } \\
\text { Reschedule the } \\
\text { delivery }\end{array}$ & $\begin{array}{l}\text { Delivery } \\
\text { exceptions } \\
\text { monitoring and } \\
\text { handling are } \\
\text { human based, } \\
\text { which is inefficient } \\
\text { (not real time and } \\
\text { time-consuming to } \\
\text { handle) and error } \\
\text { prone (human } \\
\text { errors) }\end{array}$ & $\begin{array}{l}\text { Grosof and } \\
\text { Poon } 2004 \\
\text { Hall and Potts } \\
2003 \\
\text { Helo et al. } \\
2006 \\
\text { Özkohen and } \\
\text { Yolum } 2006 \\
\text { Zimmer } 2002\end{array}$ \\
\hline $\begin{array}{l}\text { Poor } \\
\text { system } \\
\text { data quality } \\
\text { (incorrect } \\
\text { data or } \\
\text { missing } \\
\text { data) }\end{array}$ & $\begin{array}{l}\text { Human error } \\
\text { People are lazy, } \\
\text { sometimes just } \\
\text { copy and paste } \\
\text { System not } \\
\text { updated } \\
\text { System error }\end{array}$ & $\begin{array}{l}\text { Check the } \\
\text { data to find } \\
\text { out the correct } \\
\text { information and } \\
\text { fix everything } \\
\text { Overwrite the data }\end{array}$ & $\begin{array}{l}\text { System data } \\
\text { exceptions } \\
\text { monitoring and } \\
\text { handling are } \\
\text { human based, } \\
\text { which is inefficient } \\
\text { and error prone }\end{array}$ & $\begin{array}{l}\text { Dejonckheere } \\
\text { et al. } 2002 \\
\text { Lee et al. } \\
1997 \\
\text { Piramuthu } \\
2004\end{array}$ \\
\hline
\end{tabular}

\section{Logistics exceptions classification by the Cynefin sense-making framework}

Based on the literature review and the case study results, no particular complex or chaotic logistics exceptions were identified. ${ }^{2}$ Therefore, in this study, only the known and knowable logistics exceptions are studied. Based on the review in Table 9.2 and the descriptions in Table 9.3, the six identified logistics exceptions are classified into known and knowable - shown in Table 9.4 with some justifications. In addition, based on the 'Cause of the exception' in Table 9.3, the 'Monitoring factors for logistics EM' are identified in Table 9.4. These factors

1 For the full logistics exceptions analysis, please contact the authors.

2 The interviewees did not identify any complex or chaotic exceptions in their business operations. There is also no literature alluding to such situations in the logistics domain. There might be two explanations: 1) people will not treat the exceptions they have already resolved as complex or chaotic exceptions. They will put them into either known or knowable categories. The complex exceptions might still exist, but people either are not aware of them or treat them as something other than exceptions. 2) Logistics is a mature industry. All operations or business processes are well modelled. There might be no unknown events to disturb the normal business operations. 
will be used to monitor the logistics exceptions in the EM system. Similarly, based on the 'Current exception handling method' in Table 9.3, the 'Business rules for logistics EM' are formulated in Table 9.4. These business rules are used as the guidance to define the business rules and logic in the logistics EM system. How our approach addresses the problems of current handling methods is also summarised. Following the previous two logistics exception examples, the classification, factors and business rules for logistics EM are shown in Table 9.4.

Table 9.4 Exceptions classification, factors and business rules for logistics EM

\begin{tabular}{|c|c|c|c|c|}
\hline Exception & $\begin{array}{l}\text { Exception } \\
\text { classification }\end{array}$ & $\begin{array}{l}\text { Monitoring } \\
\text { factors for } \\
\text { logistics EM }\end{array}$ & $\begin{array}{l}\text { Business rules for } \\
\text { logistics EM }\end{array}$ & $\begin{array}{l}\text { How to } \\
\text { address the } \\
\text { problems }\end{array}$ \\
\hline $\begin{array}{l}\text { Delayed } \\
\text { delivery } \\
\text { or no } \\
\text { delivery }\end{array}$ & $\begin{array}{l}\text { Knowable } \\
\text { Justification: } \\
\text { Multiple indicators to } \\
\text { monitor } \\
\text { When exception } \\
\text { occurs, it requires } \\
\text { additional information } \\
\text { to re-estimate the } \\
\text { delivery time } \\
\text { When handling the } \\
\text { delayed delivery, } \\
\text { extra information and } \\
\text { analysis are required }\end{array}$ & $\begin{array}{l}\text { Weather } \\
\text { condition } \\
\text { Traffic status } \\
\text { Delivery } \\
\text { milestones } \\
\text { Space } \\
\text { availability } \\
\text { Driver status } \\
\text { Customs } \\
\text { clearance } \\
\text { status }\end{array}$ & $\begin{array}{l}\text { If exception } \\
\text { occurs, gather } \\
\text { more information, } \\
\text { recalculate the } \\
\text { estimated time for } \\
\text { delivery and alert the } \\
\text { EM personnel } \\
\text { If there is going to } \\
\text { be delay, gather } \\
\text { more information, } \\
\text { recalculate the } \\
\text { delivery routes, use } \\
\text { alternative transport } \\
\text { or reschedule the } \\
\text { delivery with the } \\
\text { clients }\end{array}$ & $\begin{array}{l}\text { By using } \\
\text { the logistics } \\
\text { EM system, } \\
\text { the delivery } \\
\text { exceptions } \\
\text { monitoring } \\
\text { and handling } \\
\text { will be } \\
\text { automated, } \\
\text { in real time, } \\
\text { more efficient } \\
\text { and more } \\
\text { accurate }\end{array}$ \\
\hline $\begin{array}{l}\text { Poor } \\
\text { system } \\
\text { data } \\
\text { quality } \\
\text { (incorrect } \\
\text { data or } \\
\text { missing } \\
\text { data) }\end{array}$ & $\begin{array}{l}\text { Known to knowable } \\
\text { Justification: } \\
\text { If the system data } \\
\text { are incomplete, it is } \\
\text { a known exception; } \\
\text { follow the routine to } \\
\text { alert the EM personnel } \\
\text { It could require } \\
\text { the acquisition of } \\
\text { additional information } \\
\text { to analyse whether } \\
\text { the system data } \\
\text { are accurate, which } \\
\text { makes it a possible } \\
\text { knowable exception }\end{array}$ & $\begin{array}{l}\text { System data } \\
\text { completeness } \\
\text { System data } \\
\text { accuracy } \\
\text { System status }\end{array}$ & $\begin{array}{l}\text { If anything goes } \\
\text { wrong (that is, } \\
\text { exception occurs), } \\
\text { alert the EM } \\
\text { personnel and } \\
\text { provide them with } \\
\text { evidence of the } \\
\text { correct data }\end{array}$ & $\begin{array}{l}\text { By using } \\
\text { the logistics } \\
\text { EM system, } \\
\text { the system } \\
\text { exceptions } \\
\text { monitoring } \\
\text { and handling } \\
\text { will be } \\
\text { automated } \\
\text { in real time, } \\
\text { more efficient } \\
\text { and more } \\
\text { accurate }\end{array}$ \\
\hline
\end{tabular}




\section{Logistics exception management conceptual framework development}

Based on the basic BAM logical layered architecture (see Figure 9.2), in order to provide a more efficient and effective decision support framework for logistics EM and inform the logistics EM system design, the classification of logistics problems/exceptions (see section four, 'Logistics exceptions classification') is added to this BAM architecture. According to the logistics exceptions classification, the appropriate courses of action can be determined to speed up the logistics EM process for decision making. The logistics EM conceptual framework is shown in Figure 9.3.

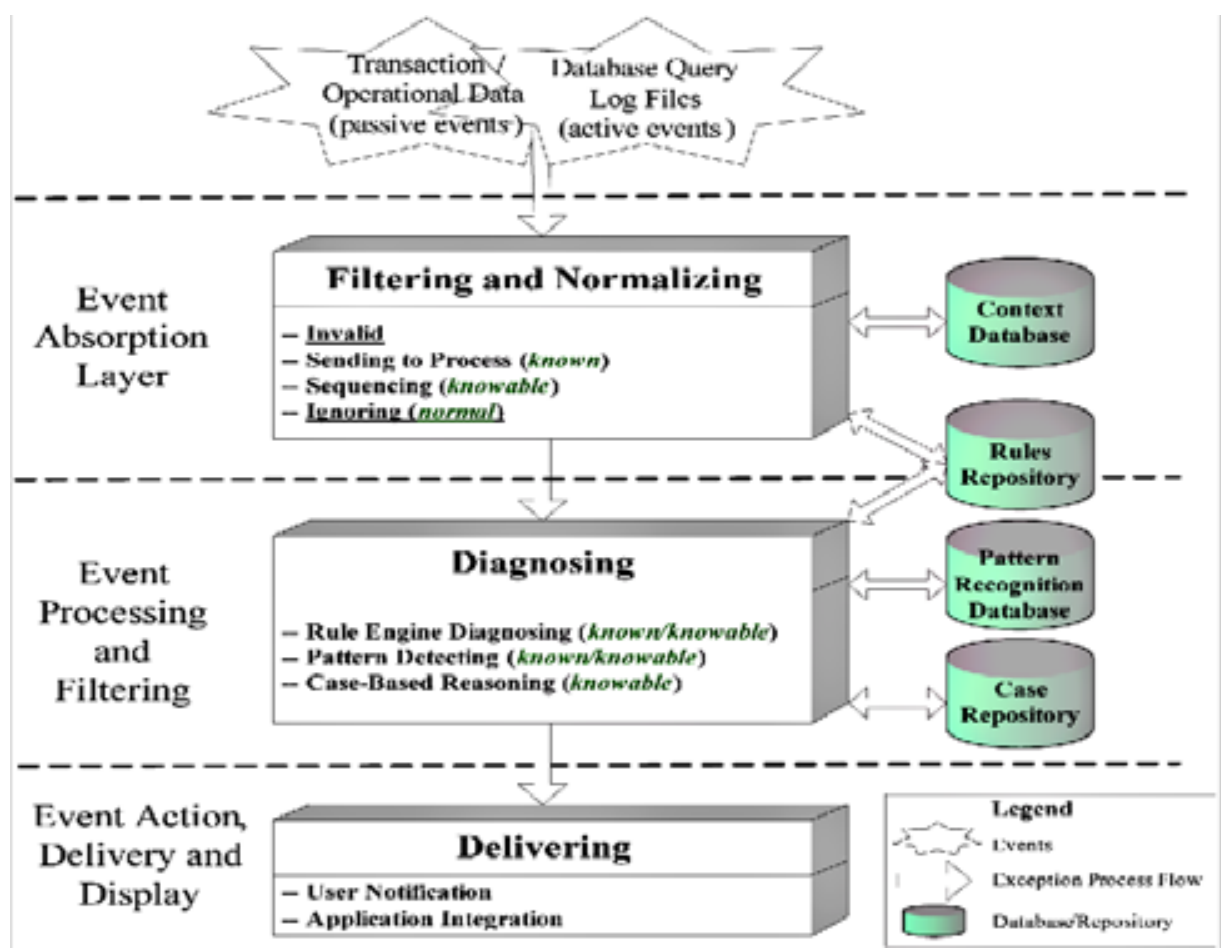

Figure 9.3 Logistics EM conceptual framework

\section{Event absorption layer}

In this layer, the logistics EM system first collects logistics events and prepares them to be analysed. Logistics events can be obtained through active or passive means. Passive events are those that are subscribed to. Active events are created by an agent or adapter who might poll applications and databases for changes and threshold crossings. Once the logistics event has been received, it needs to be validated first; an invalid event will not be processed further. The logistics 
event is then filtered for relevancy. The majority of events are normal events that require no action. The EM system will ignore these events; they are not for processing. Some logistics events are problematic or exceptional events, which are the activities that need to be monitored. They are further categorised into: 1) sending to next layer for diagnosing, which are known exceptions. The system knows how to handle them by applying rules or matching them with known patterns. 2) Sequencing, which are knowable exceptions. As long as more information is obtained, they will be sent for further diagnosis.

\section{Event processing and filtering layer}

The event processing and filtering layer is the most important layer of a logistics EM system. The scope of this research is on monitoring the known and knowable problems/exceptions. In Figure 9.3, however, there are not many details to show the different diagnostic processes for known and knowable exceptions. Informed by Simon's (1977) problem-solving/decision-making process and the Cynefin (Snowden 2002) decision model, the detailed diagnostic processes for known and knowable logistics exceptions are described below.

When a known logistics exception is detected, according to the Cynefin decision model (Snowden 2002), it will be categorised based on the relevant rules and patterns. As the known logistics exceptions have been fully understood and well modelled, a corresponding resolution report (containing one resolution) based on a priori established procedures will be issued to the handling personnel for execution. This process is portrayed in the top half of Figure 9.4. As a decisionmaking process, referring to Simon's (1977) process theory, the categorisation belongs to the design phase, as the exceptions are structured and the criteria are developed, while the release of the resolution report and execution represent the choice phase, as the decision has been made and executed. After the personnel have handled the known logistics exception, the rules and patterns are accumulated and organised in the rule repository and pattern recognition database.

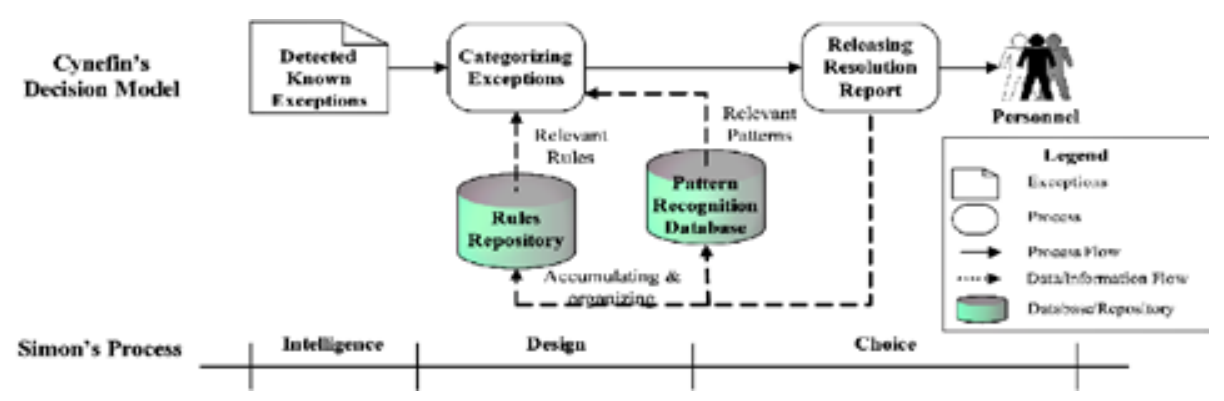

Figure 9.4 Diagnostic process for known logistics exceptions 
When a knowable logistics exception is detected, additional information is retrieved and the search and navigation process in the case repository is initiated. The case repository will provide the relevant past logistics cases that are useful references for evaluating the detected known or knowable logistics exception. According to the Cynefin decision model (Snowden 2002), the knowable logistics exception will be analysed based on past similar cases, relevant rules and patterns. Because of the complicated nature of the event and insufficient information, no single solid solution will be provided after the analysis. Instead, a number of possible alternatives will be generated. The handling personnel will be the final decision makers determining which alternative to choose as the best solution to handle the exception. In such a decision-making process, referring to Simon's (1977) process theory, the analysis and alternative generation are in the design phase, as the problems/exceptions are structured, the criteria are developed and the alternatives are identified. The human decision making is the choice phase, as the human decision maker chooses the best alternative that meets the criteria, and makes the final decision. After the personnel have handled the knowable logistics exception, the case is accumulated and organised in the case repository along with the associated rules and patterns. The diagnostic process for knowable logistics exceptions is portrayed in Figure 9.5.

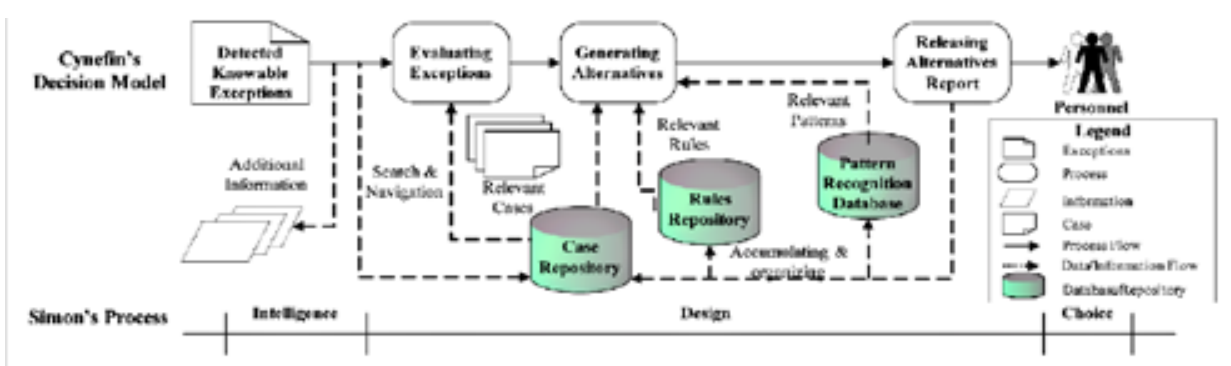

Figure 9.5 Diagnostic process for knowable logistics exceptions

\section{Event action, delivery and display layer}

In this last layer, the output of a logistics EM system is an alert or notification. It can be sent to a person or linked with another process.

\section{Logistics exception management multi-agent system architecture development}

To illustrate the proposed logistics EM conceptual framework, the design of a multi-agent-based logistics EM system is presented in this section. This design architecture aims to automate the monitoring, diagnosis and reporting of 
logistics exceptions so as to assist a logistics operator to gain quicker results. The logistics EM conceptual framework is applied by delegating logistics EM tasks to a collection of agents. Each agent plays a role in logistics EM and is in charge of specific tasks. The logistics EM system architecture is portrayed in Figure 9.6, which describes the internal interactions among agents and the external relationships between the logistics EM system and legacy logistics operation systems. Based on the logistics EM conceptual framework (Figure 9.3), Figure 9.6 is also classified into three layers. According to the detailed diagnostic process (Figures 9.4 and 9.5), intelligent agents in Figure 9.6 are deployed by Simon's (1977) problem-solving/decision-making process, in which the design group agents and their processes are derived from the Cynefin sense-making framework (Snowden 2002).

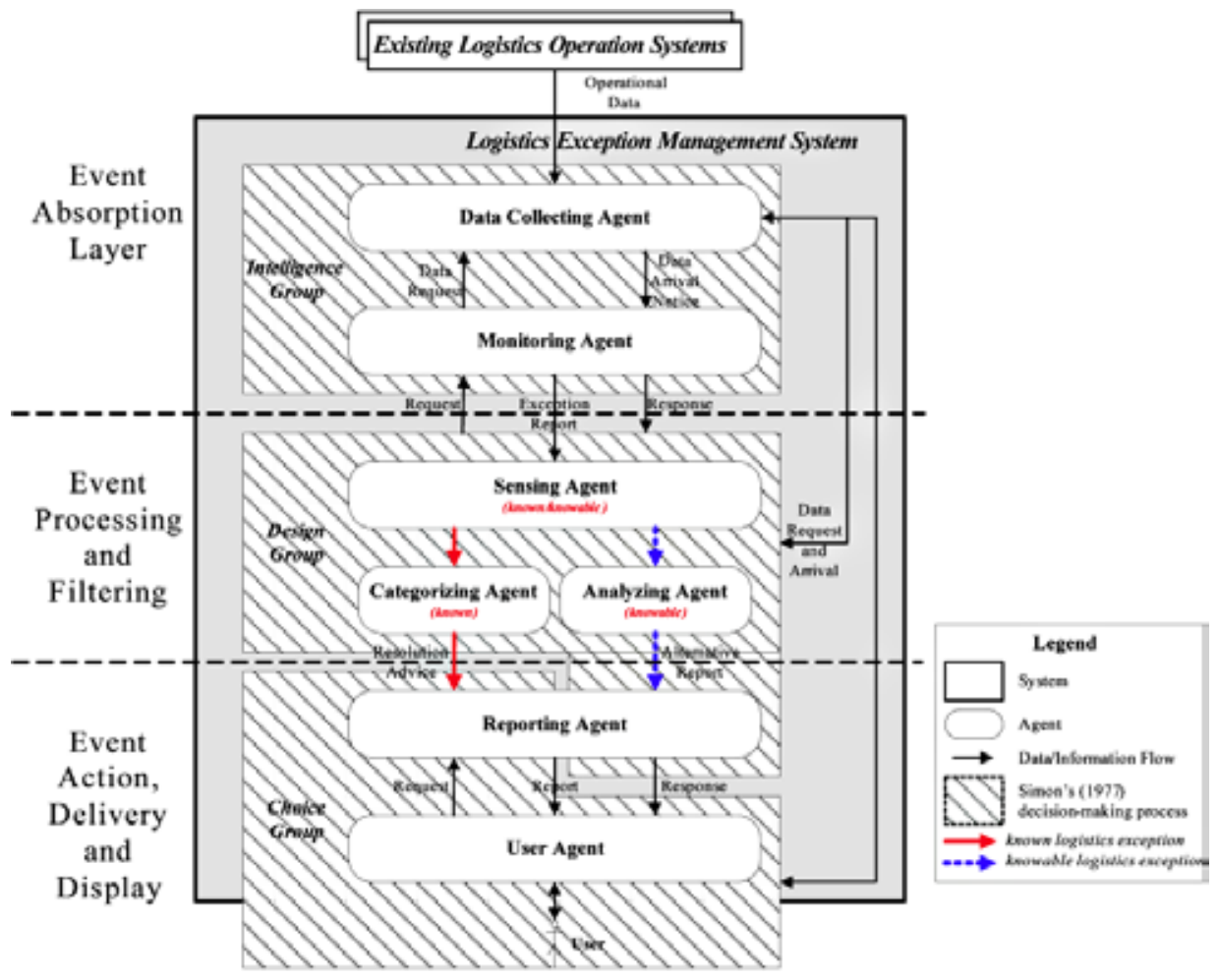

Figure 9.6 Logistics EM system architecture

The agents are distributed in the organisations or departments involved in logistics. All these agents work autonomously and collaboratively in the multi-agent environment. The user agent acts as an effective bridge between the user and the computer. It can make the human-computer interface more intuitive and encourage types of interactions that might be difficult to evoke with a conventional interface. In the system, this agent enables users to view 
the current state of the operations and exception monitoring, diagnostic and reporting processes and allows them to convey their own judgments, opinions and arguments relative to logistics EM to the rest of the organisation. The agent also enables the corresponding users to issue requests to the other agents in the system.

The intelligence group contains two agents: the data-collecting agent enables the system to collect data. The subsequent design and choice groups may request information relating to their task from the data-collecting agent, if required. The monitoring agent monitors the logistics operations. When the monitoring agent captures a possible exception, it will classify the exception into known or knowable, based on predefined business rules and logic (see Table 9.4). The output of the monitoring agent is an exception report, which will be sent to the sensing agent for diagnosis.

- Known exceptions will be categorised by applying the rules and existing patterns by the categorising agent. Then it will issue a resolution advice with a priori established procedures.

- Knowable exceptions will be analysed by the analysing agent based on: 1) exception reports from the monitoring agent; and 2) any additional information, if necessary, to examine the case. The analysing agent adopts a case-based reasoning and rule-based approach. After the analysis, an alternative report will be generated.

Different agents will process different types of exceptions, which are indicated by different colours and types of arrows in Figure 9.6. Different kinds of reports will be sent to the reporting agent as deliverables. The reporting agent will present and communicate the report to the appropriate personnel through the user agent for EM investigation and action. Alternatively, the reporting agent will automate or take a specific action. Complicated exceptions for investigation are filtered and prioritised based on the severity of the exceptions to the business. The reporting agent is able to support the business process to assist with exception investigation by providing all relevant past cases and information, ensuring the exception handling personnel have all of the relevant information at hand for decision making.

\section{Evaluation}

As the designed system is purposeful, it should yield value for logistics EM users in making decisions for solving logistics exceptions more effectively. In the later stage of this research, a prototype system based on the system architecture will be implemented. Hevner et al. (2004) identify five classes of methods for 
evaluating designed artefacts. To evaluate the performance of exception handling decision making, this research uses the first class of evaluation, observational (comprising case studies and field studies), and the third class, experimental (comprising controlled experiments and simulation), as follows.

1. We will conduct a confirmatory case study with the same logistics staff in the same logistics company to investigate whether they are satisfied with the prototype system. Semi-structured interviews with all previous interviewed logistics staff (seven to nine people) will be conducted. Each interview will last for one to two hours. During the interview, the conceptual framework and system architecture will be explained and the prototype system will be tested by the interviewees. Semi-structured questions will be designed based on the prior literature. Feedback on the artefacts, regarding the system design and decision support effectiveness of the prototype, will be obtained, coded (by using QSR Nvivo) and analysed in order to refine them.

2. A laboratory experiment will be conducted to evaluate the system EM decision support effectiveness. The decision-making effectiveness of people supported by the proposed agent-based logistics EM system will be compared with people without the system support. The subjects will be recruited from the same logistics company, but will be from different teams. A total of at least 60 subjects will be recruited. The subjects will be randomly assigned to one of the two groups: treatment group — with logistics EM system support; and control group - without logistics EM system support. Sprague and Carlson (Sprague 1982) describe four major categories-productivity, process, perception and product measures - which have proven to be valid evaluation models of decision support system effectiveness in research (Gao et al. 2007; Sainfort et al. 1990; Sharda et al. 1988; Vahidov and Fazlollahi 2004). Based on this logistics EM decision-making research domain-and following on from this successful approach - the proposed agent-based logistics EM system will be examined in the sense that it improves (or does not improve) the process, outcomes and user perceptions regarding decision making. A set of logistics exception handling tasks will be designed based on the existing business cases (collected from the exploratory case study described in the 'Exception analysis' subsection). Before the laboratory experiment, a pilot study will be conducted with a small group of logistics experts to test the experimental protocol. The feedback from the pilot study will be used to refine the experimental protocol. During the laboratory experiment, two groups will do the same tasks, followed by the completion of a questionnaire that tests their perceptions. Both groups will see the same logistics exception case simulation. When a logistics exception occurs, however, the controlgroup participants will need to resolve the exception by themselves while the treatment-group participants will receive the exception report, which includes the nature of the exception, the cause of the exception and the 
resolution/alternatives for resolution of the exceptions. Both groups need to make a decision regarding how to resolve the exception. The decisionmaking process will be measured by the time used to make the decision and the number and quality of the alternatives generated. The decision outcome will be measured for the final decision quality. The user perceptions will be measured by the quantitative analysis of the questionnaire data. The general expectation is that the decision-making effectiveness of the people who are supported by the theory-driven agent-based logistics EM system will be higher than that of the people without the system support.

\section{Research summary}

With the increased complexity, uncertainty and risks in business operations, adaptive and collaborative business process and EM are gaining growing attention in business applications. This chapter has presented design-science research that aims to understand logistics exceptions, provide a real-time decision-making mechanism to monitor and handle the logistics exceptions in an efficient way and has proposed a comprehensive decision-support system architecture for logistics EM. This research creates and will evaluate two ITdesigned artefacts (conceptual framework and prototype) intended to efficiently and automatically monitor and handle logistics exceptions, which is designscience research according to Hevner et al. (2004). Two designed artefacts are strictly informed by, and incorporated with, three different theories: Simon's (1977) decision-making/problem-solving process, the Cynefin sense-making framework and decision models (Snowden 2002) and Gartner's BAM architecture (Dresner 2003). The exploratory case study (the 'Exception analysis' subsection) and the later design evaluation (the 'Evaluation' section) follow Yin's (2003) case study methodology and experimental design methodology. The results of the evaluation will be used to refine the designed artefacts. Such a buildand-evaluate loop will iterate several times before the final design artefact is generated. The research includes technical presentation and practical framing in terms of application in the logistics exception monitoring and handling domain.

There are three research phases, each focusing on a different research perspective and forming the prerequisite foundation for the next research phase.

The first research phase focuses on the conceptualisation of the logistics EM. It consists of two parts. The first part is logistics exceptions classification, in order to enable more efficient decision-support practices for logistics EM. The second part focuses on the development of the conceptual framework (an artefact) for design and development of a logistics EM system for decision making. This is informed by sense-making theory (Snowden 2002), decision-making process 
theory (Simon 1977) and BAM architecture (Dresner 2003). In this research phase, the research problem is recognised, relevant theories are studied and the conceptual framework is constructed.

The second research phase focuses on the formalisation of the conceptual framework. A multi-agent-based logistics EM system is designed based on the conceptual framework, whereby system users can be notified and provided with decision support for handling logistics exceptions in real time.

The third research phase will focus on the development of the designed logistics EM artefact. It will include two stages. First, a prototype will be developed. To provide a more adaptive, flexible and collaborative decision support, intelligent agent technology will be used for implementation. Second, the prototype will be evaluated via social-science research methods: semi-structured interviews and laboratory experiment. It is proposed that this theory-driven agent-based logistics EM system will provide more efficient and timely decision-making support for the managers in relation to logistics EM.

The designed artefacts and the research design are the major contribution of this research. The artefacts are the real-time extension of Simon's (1977) classic decision-making/problem-solving process model in logistics EM by incorporating BAM (Dresner 2003). In addition, by adding the Cynefin sensemaking framework, the artefacts provide a more efficient decision-making routine for logistics EM. The three theory-driven artefacts are believed to enable efficient real-time decision making in the logistics EM domain. In addition, the logistics EM conceptual framework can be applied to other EM situations, such as fraud detection, compliance with regulations, anomalies detection, and the like. In this chapter, we apply the conceptualisation-formalisation-development research approach in the logistics EM decision support domain. We argue that the same research approach can be applied in other similar IS design-science research. In practice, the logistics exceptions classification, logistics EM conceptual framework and incorporation of agent technologies into logistics EM will assist logistics companies to develop their logistics exception handling decision-making strategies and solutions.

\section{References}

Arnott, D. 2006, 'Cognitive biases and decision support systems development: a design science approach', Information Systems Journal, vol. 16, pp. 55-78.

Becker, T. J. 2000, 'Putting a price on supply chain problems: study links supply chain glitches with falling stock price', Georgia Tech Research News, <http:// gtresearchnews.gatech.edu/newsrelease/CHAINR.html> 
Dejonckheere, J., Disney, S. M., Lambrecht, M. R. and Towill, D. R. 2002, 'The impact of information enrichment on the bullwhip effect in supply chains: a control engineering perspective', European Journal of Operational Research, vol. 153, no. 3, pp. 727-50.

Dellarocas, C. and Klein, M. 2000, 'A knowledge-based approach for designing robust business processes', in W. van der Aalst, J. Desel and A. Oberweis (eds), Business Process Management, Models, Techniques, and Empirical Studies, Springer, Berlin, pp. 60-5.

Dellarocas, C., Klein, M. and Rodriguez-Aguilar, J. A. 2000, 'An exception handling architecture for open electronic marketplaces of contract net software agents', Proceedings of the ACM Conference on Electronic Commerce, pp. 225-32.

Dresner, H. 2003, 'Business activity monitoring: BAM architecture', Gartner, $<$ http://www.pikos.net/documents/german/Gartner.pdf>

Dutta, A. 1996, 'Integrating AI and optimization for decision support: a survey', Decision Support Systems, vol. 18, nos 3-4, pp. 217-26.

Gallupe, R. B., Desanctis, G. and Dickson, G. W. 1988, 'Computer-based support for group problem-finding: an experimental investigation', MIS Quarterly, vol. 12, no. 2, pp. 277-96.

Gao, S., Wang, H., Wang, Y., Shen, W. and Yeung, S. 2005, 'Web-service-agentsbased family wealth management system', Expert Systems with Application, vol. 29, no. 1, pp. 219-28.

Gao, S., Wang, H., Xu, D. and Wang, Y. 2007, 'An intelligent agent-assisted decision support system for family financial planning', Decision Support Systems, vol. 44, no. 1, pp. 60-78.

Gregg, D. G., Kulkarni, U. R. and Vinze, A. S. 2001, 'Understanding the philosophical underpinnings of software engineering research in information systems', Information Systems Frontiers, vol. 3, pp. 169-83.

Grosof, B. N. and Poon, T. C. 2004, 'SweetDeal: representing agent contracts with exceptions using semantic web rules, ontologies, and process descriptions', International Journal of Electronic Commerce, vol. 8, no. 4, pp. 61-97.

Hall, N. G. and Potts, C. N. 2003, 'Supply chain scheduling: batching and delivery', Operations Research, vol. 51, no. 4, pp. 566-84.

Helo, P., Xiao, Y. and Jiao, J. R. 2006, 'A web-based logistics management system for agile supply demand network design', Journal of Manufacturing Technology Management, vol. 17, no. 8, pp. 1058-77. 
Hevner, A. R., March, S. T., Park, J. and Ram, S. 2004, 'Design science in information systems research', MIS Quarterly, vol. 28, no. 1, pp. 75-105.

Huhns, M. N., Stephens, L. M. and Ivezic, N. 2002, 'Automating supplychain management', Proceedings of the 1st International Joint Conference on Autonomous Agents and MultiAgent Systems (AAMAS), ACM Press, pp. 1017-24.

Jennings, N. 2000, 'On agent-based software engineering', Artificial Intelligence, vol. 117, no. 2, pp. 227-96.

Jennings, N. and Wooldridge, M. 1998, Agent Technology: Foundations, applications, and markets, Springer-Verlag, Berlin.

Jennings, N., Faratin, P., Norman, T., O'Brien, P. and Odgers, B. 2000, 'Autonomous agents for business process management', International Journal of Applied AI, vol. 14, no. 2, pp. 145-89.

Kammer, P., Bolcer, G., Taylor, R., Hitomi, A. and Bergman, M. 2000, ‘Techniques for supporting dynamic and adaptive workflow', Computer Supported Cooperative Work, vol. 9, nos 3-4, pp. 269-92.

Klein, M. and Dellarocas, C. 2000, 'A knowledge-based approach to handling exceptions in workflow systems', Computer Supported Cooperative Work, vol. 9, nos 3-4, pp. 399-412.

Klein, M., Dellarocas, C. and Bernstein, A. 2000, 'Introduction to the special issue on adaptive workflow systems', Computer Supported Cooperative Work, vol. 9, nos 3-4, pp. 265-7.

Kuo, M. H. and Lin, M. J. 2000, 'Using software agents to retrieve information from WWW', SCI'2000, Orlando, Fla, pp. 400-5.

Kurtz, C. F. and Snowden, D. 2003, 'The new dynamics of strategy: sense-making in a complex and complicated world', IBM Systems Journal, vol. 42, no. 3, pp. $462-83$.

Lee, H. L., Padmanabhan, V. and Whang, S. 1997, 'Information distortion in a supply chain: the bullwhip effect', Management Science, vol. 43, no. 4, pp. 546-58.

Liu, K., Sun, L., Dix, A. and Narasipuram, M. 2001, 'Norm based agency for designing collaborative information systems', Info Systems Journal, vol. 11, no. 3, pp. 229-47.

McCoy, D. W. 2002, 'Business activity monitoring: calm before the storm', Gartner, <http://www.gartner.com/resources/105500/105562/105562.pdf> 
McKeefrey, H. L. 2002, 'Business intelligence goes real-time', VARBusiness, $<$ http://www.crn.com/it-channel/18828781>

March, S. and Smith, G. F. 1995, 'Design and natural science research on information technology',Decision Support Systems, vol. 15, pp. 251-66.

Mark, A. L. 2006, 'Notes from a small island: researching organizational behavior in healthcare from a UK perspective', Journal of Organizational Behavior, vol. 27, no. 7, pp. 851-67.

Moitra, D. and Ganesh, J. 2005, 'Web services and flexible business processes: towards the adaptive enterprise', Information \& Management, vol. 42, no. 7, pp. 921-33.

Nesamoney, D. 2004, 'BAM: event-driven business intelligence for the real-time enterprise', DM Review, vol. 14, no. 3, pp. 38-40.

Nunamaker, J. F. jr, Chen, M. and Purdin, T. D. M. 1991, 'Systems development in information systems research', Journal of Management Information Systems, vol. 7, no. 3, pp. 89-106.

O'Neill, L. 2004, 'Faith and decision-making in the Bush presidency: the god elephant in the middle of America's living-room', $E$ : $C O$, vol. 6, no. 1, pp. 149-56.

Özkohen, A. and Yolum, P. 2006, 'Predicting exceptions in agent based supply chains', Engineering Societies in the Agents World VI Lecture Notes in AI, vol. 3963, pp. 168-83.

Parameswaran, P. 2004, 'Business activity monitoring (BAM) - the future of business intelligence', DM Direct, <http:/www.dmreview.com/ dmdirect/20041008/1011668-1.html>

Piramuthu, S. 2004, 'Knowledge-based framework for automated dynamic supply chain configuration-production, manufacturing and logistics', European Journal of Operational Research, vol. 165, no. 1, pp. 219-30.

Sainfort, F. C., Gustafson, D. H., Bosworth, K. and Hawkins, R. P. 1990, 'Decision support systems effectiveness: conceptual framework and empirical evaluation', Organizational Behavior and Human Decision Processes, vol. 45, no. 2, pp. 232-52.

Sharda, R., Barr, S. H. and McDonnell, J. C. 1988, 'Decision support system effectiveness: a review and an empirical test', Management Science, vol. 34, no. 2, pp. 139-59. 
Simon, H. A. 1977, The New Science of Management Decision, Prentice-Hall, Upper Saddle River, NJ.

Snowden, D. 2002, 'Complex acts of knowing: paradox and descriptive selfawareness', Journal of Knowledge Management, vol. 6, no. 2, pp. 100-11.

Snowden, D. 2004, 'Facilitating innovation within the organization', Finance \& Management, pp. 5-7.

Sprague, R. and Carlson, E. D. 1982, Building Effective Decision Support Systems, Prentice-Hall, Upper Saddle River, NJ.

Stewart, T. A. 2002, 'How to think with your gut', Business 2.0, < http://www. cognitive-edge.com/ceresources/articles/49_Thinking_with_your_Gut(T_ Stewart_article_in_Bus_2).pdf $>$

Vahidov, R. 2005, 'Intermediating user-DSS interaction with autonomous agents', IEEE Transaction on System, Man, and Cybernetics-Part A: System and humans, vol. 35, no. 6, pp. 964-70.

Vahidov, R. and Fazlollahi, B. 2004, 'Pluralistic multi-agent decision support system: a framework and an empirical test', Information \& Management, vol. 41, no. 7, pp. 883-98.

Wang, H., Mylopoulos, J. and Liao, S. 2002, 'Intelligent agents and financial risk monitoring systems', Communications of the ACM, vol. 45, no. 3, pp. 83-8.

Wang, M. and Wang, H. 2006, 'From process logic to business logic - a cognitive approach to business process management', Information \& Management, vol. 43, no. 2, pp. 179-93.

Wooldridge, M. 2002, An Introduction to Multiagent Systems, J. Wiley, New York.

Wooldridge, M. and Jennings, N. R. 1995, 'Intelligent agents: theory and practice', Knowledge Engineering Review, vol. 10, no. 2, pp. 115-52.

Yin, R. 2003, Case Study Research: Design and methods, Third edition, Sage, Thousand Oaks, Calif.

Zimmer, K. 2002, 'Supply chain coordination with uncertain just-in-time delivery', International Journal of Production Economics, vol. 77, no. 1, pp. 1-15. 